\title{
VIGOR DE SEMENTES DE RÚCULA (Eruca sativa L.) PELO TESTE DE DETERIORAÇÃO CONTROLADA ${ }^{1}$
}

\author{
LIZIANE SILVA GOULART² ${ }^{2}$ MARIA ANGELA ANDRÉ TILLMANN³
}

\begin{abstract}
RESUMO - O presente trabalho teve o objetivo de estudar procedimentos para condução do teste de deterioração controlada para determinar o potencial fisiológico de sementes de rúcula. Foram utilizados dois lotes de sementes envelhecidos artificialmente, obtendo-se para cada lote, seis níveis de qualidade. As sementes foram submetidos aos testes de germinação, primeira contagem da germinação, comprimento de plântulas, classificação de vigor de plântulas, envelhecimento acelerado com e sem solução saturada de $\mathrm{NaCl}$, emergência em campo e deterioração controlada. Para determinação da melhor combinação de temperatura e teor de água a serem utilizados no teste de deterioração controlada foram testadas duas temperaturas $\left(41\right.$ e $\left.45^{\circ} \mathrm{C}\right)$ e dois níveis de teor de água (20 e 24\%). O teste de deterioração controlada conduzido a $41^{\circ} \mathrm{C}$, com umidade das sementes de $20 \%$ e período de exposição de 24 h é eficiente para avaliar o potencial fisiológico de sementes de rúcula.
\end{abstract}

Termos para indexação: hortaliça, sementes, potencial fisiológico.

\section{VIGOR OF SALAD ROCKET(Eruca sativa L.) SEEDS BY CONTROLLED ETERIORATION TEST}

\begin{abstract}
The objective of the present study was to investigate the procedure for the conducting the controlled deterioration test to evaluate the physiological quality of salad rocket (Eruca sativa L.) seeds, cv. Cultivada. Two lots of salad rocket seeds were tested for germination, first germination count, seedling length, accelerated aging with and without the use of saturated $\mathrm{NaCl}$ solution, field emergence and controlled deterioration. Two temperatures $\left(41\right.$ and $\left.45^{\circ} \mathrm{C}\right)$ and two moisture contents (20 and 24\%) were tested to obtain the best relationship between temperature and moisture content for use in the controlled deterioration test for salad rocket. The controlled deterioration test conducted at $41^{\circ} \mathrm{C}$, for 20 and $24 \%$ and 24 h was efficient in evaluating the physiological quality of salad rocket seeds, cv. Cultivada.
\end{abstract}

Index terms: vegetable, seeds, physiological potential.

\section{INTRODUÇÃO}

A rúcula, hortaliça da família Brassicaceae, originou-se no sul da Europa e na parte ocidental da Ásia. Relata-se também o cultivo dessa espécie pelos romanos, antes do nascimento de Cristo (Yamaguchi, 1978). No estado de São Paulo, o consumo da rúcula tem aumentado a cada ano, sendo que em 1997, o CEAGESP recebeu para comercialização 140 mil dúzias de maços e em 2001 aumentou para 448 mil, com previsão de crescimento para os próximos anos. O volume comercializado triplicou no período de 1997 a 2000 indicando

\footnotetext{
${ }^{1}$ Submetido em 12/03/2006. Aceito para publicação em 13/04/2007. Parte da Dissertação de Mestrado da primeira autora, apresentada ao Programa de Pós Graduação em Ciência e Tecnologia de Sementes, FAEM/ UFPEL.

${ }^{2}$ Eng $^{\mathrm{a}}$. Agr ${ }^{\mathrm{a}}$., MSc., Doutoranda em Ciência \& Tecnologia de Sementes,
}

o interesse por parte da população e comprovando sua importância econômica entre as demais hortaliças folhosas.

A produção brasileira de sementes de hortaliças ganhou maior impulso no final dos anos 1990, principalmente, pela atuação de empresas multinacionais no mercado. Essa situação decorreu da busca de novos conhecimentos para a produção de sementes de hortaliças, em parte incorporados aos disponíveis para espécies de grandes culturas, em que o grau tecnológico da produção nacional é comparável ao predominante em países considerados mais desenvolvidos. Inicialmente, as pesquisas voltaram-se, de modo mais

Depto. de Fitotecnia FAEM/UFPel. Pelotas - RS

${ }^{3}$ Eng $^{\text {a }}$. Agra . Dra. Profa. Associada Depto. Fitotecnia. Faculdade de Agronomia Eliseu Maciel. UFPel. Pelotas - RS. 
intensivo, para a introdução de materiais genéticos adaptados às condições de produção do Brasil. Após a fase de adequação inicial dos cultivares, sistemas de produção, embalagens e comercialização, têm emergido a demanda por pesquisas que forneçam informações capazes de permitir apoio ao controle de qualidade durante as diferentes etapas do processo de produção de sementes. Desta maneira, verificam-se esforços direcionados ao estudo de métodos para estimativa do vigor de sementes.

Os testes de vigor são cada vez mais relevantes para sementes de hortaliças, viabilizando a prática de semeadura de precisão, a eliminação do desbaste e a obtenção de uniformidade de desenvolvimento e maturação de plantas. Para tanto, as sementes devem exibir potencial fisiológico elevado, tornando necessário o emprego rotineiro de testes de vigor em programas de controle de qualidade (Hampton e Coolbear, 1990).

A uniformidade de emergência é muito importante no cultivo de hortaliças em razão do alto custo das sementes e da mão-de-obra exigida durante o seu cultivo (Globirson,1981). Em determinadas culturas, como a da alface, a desuniformidade na emergência pode resultar na necessidade de serem efetuadas colheitas sucessivas e acarretar irregularidade de tamanho do produto colhido (Wurr e Fellous, 1983).

O teste de deterioração controlada segue o mesmo princípio do envelhecimento acelerado; porém, em vez do uso de ambientes com alta umidade relativa do ar, são avaliadas amostras de sementes com teor de água ajustado e semelhante, com o objetivo de conferir maior uniformidade ao teste e, conseqüentemente, padronização mais efetiva, principalmente para espécies que possuem sementes de menor tamanho. De acordo com Powell (1995), as diferenças na velocidade e intensidade de absorção de água por amostras de sementes, no teste de envelhecimento acelerado, podem ocasionar variações acentuadas no grau de umidade, especialmente em espécies que possuem sementes relativamente pequenas, o que geralmente não ocorre no teste de deterioração controlada.

No teste de deterioração controlada, a deterioração é provocada através do ajuste do grau de umidade das sementes para, no mínimo, 15,5\%, previamente à instalação do teste. As sementes umedecidas são acondicionadas em recipientes herméticos e mantidas em banho-maria, à temperatura constante $\left(40\right.$ a $\left.45^{\circ} \mathrm{C}\right)$, durante período pré-estabelecido; em seguida, são colocadas para germinar. A porcentagem de plântulas normais é considerada proporcional ao vigor das sementes (Torres, 2002).

A deterioração controlada é um teste relativamente simples, não exigindo conhecimentos sofisticados, investimentos significativos e não apresenta dificuldades acentuadas para padronização. Dessa forma, tem sido utilizado para detectar diferenças no vigor de lotes de sementes e para verificar o potencial de armazenamento de sementes de diversas hortaliças, como cenoura (Matthews, 1980), cebola (Powell e Matthews, 1981), alface (Powell e Matthews, 1984a, b), brássicas ( Wang et al., 1994), pimentão (Panobianco e Marcos Filho,1998), tomate (Rodo et al.,1998b e Panobianco e Marcos Filho 2001a) e brócolis (Sader et al.,2001).

Com essas considerações, o presente trabalho teve o objetivo de estabelecer metodologia para condução do teste de deterioração controlada para avaliação do potencial fisiológico de sementes de rúcula.

\section{MATERIALE MÉTODOS}

O presente trabalho foi conduzido no Laboratório de Análise de Sementes Dr. Flavio Farias Rocha do Departamento de Fitotecnia da Universidade Federal de Pelotas, em PelotasRS, utilizando-se sementes de rúcula (Eruca sativa L.), cultivar Cultivada. Foram conduzidos testes para avaliação do potencial fisiológico de lotes de sementes de rúcula e avaliados procedimentos para a condução do teste de deterioração controlada.

Obtenção dos níveis de qualidade dos lotes 1 e 2 dois lotes de sementes foram envelhecidos artificialmente à temperatura de $41^{\circ} \mathrm{C}$ por $6,12,18,24$ e 30 horas e alta umidade relativa. Após o envelhecimento o teor de água das sementes foi ajustado para a umidade inicial (aproximadamente 6,0\%) e as sementes avaliadas através dos testes de germinação, $1^{\text {a }}$ contagem de germinação, comprimento de plântulas, classificação de vigor de plântulas, envelhecimento acelerado tradicional e com solução saturada de $\mathrm{NaCl}$,emergência em campo e deterioração controlada.

Determinação do grau de umidade - foi realizada pelo método da estufa a $105^{\circ} \mathrm{C} \pm 3$, durante 24 horas, de acordo com as Regras para Análise de Sementes - RAS (Brasil, 1992), utilizando-se duas subamostras de 4,0g de sementes para cada lote. Os resultados foram expressos em percentagem média (base úmida) por lote.

Teste de germinação - quatro repetições de 50 sementes por lote, cada uma distribuída sobre duas folhas de papel mata-borrão, previamente umidecidas com quantidade de água equivalente a 2,5 vezes o peso do substrato seco, colocadas no interior de caixas plásticas transparentes (11,5x11,5x3,5cm). Em seguida, estas foram mantidas em germinador a $20^{\circ} \mathrm{C}$. As avaliações foram efetuadas de acordo 
com as Regras para Análise de Sementes (Brasil, 1992), aos quatro e sete dias após a semeadura, sendo os resultados expressos em percentagem média de plântulas normais para cada lote.

Primeira contagem de germinação - esses dados foram obtidos computando-se a percentagem de plântulas normais obtidas aos quatro dias após a instalação do teste de germinação. Os resultados foram expressos em percentagem média de plântulas normais para cada lote.

Comprimento de plântula - realizado com quatro subamostras de 10 sementes, semeadas no terço superior do papel toalha (germitest), previamente umedecido com água destilada, com um volume equivalente a 2,5 vezes o peso do papel, acondicionadas em forma de rolo. Estes, foram colocados em saco plástico e mantidos em germinador à $20^{\circ} \mathrm{C}$. Durante a avaliação, no quarto dia, as plântulas normais correspondentes a cada subamostra foram separadas e medidas em sua totalidade. Os valores médios obtidos a partir das médias das quatro subamostras foram expressos em centímetros

Classificação de vigor de plântulas - na primeira contagem da germinação ( $4^{\circ} \mathrm{dia}$ ), as plântulas normais bem desenvolvidas e morfologicamente perfeitas, sem rachaduras ou lesões foram computadas e classificadas como normais fortes (vigorosas). Na contagem final ( $7^{\circ}$ dias), todas as plântulas remanescentes foram avaliadas como normais ou anormais. As normais foram classificadas em fortes e em fracas. Foram consideradas como plântulas normais fracas àquelas que apresentaram algum problema em sua estrutura ou lesão, mas que não caracterizavam como anormalidade à plântula (Nakagawa, 1994). Os resultados foram expressos em percentagem de plântulas normais fortes.

Envelhecimento acelerado (procedimento tradicional) - o teste foi conduzido utilizando-se caixas plásticas transparentes $(11,5 \times 11,5 \times 3,5 \mathrm{~cm})$ como compartimentos individuais (mini-câmaras), possuindo em seu interior suportes para apoio de uma tela metálica. Na superfície de cada uma destas foram distribuídas, em camada única, cerca de 9,0g de sementes de cada lote. Para o controle da umidade relativa do ar no interior das caixas, foram colocados $40 \mathrm{~mL}$ de água. As caixas tampadas foram mantidas em "BOD” regulada a $41^{\circ} \mathrm{C}$, durante 48 horas. Decorrido o período de envelhecimento, quatro subamostras de 50 sementes por tratamento foram colocadas para germinar, seguindo o mesmo procedimento utilizado para o teste de germinação. A avaliação foi realizada aos quatro dias após a semeadura, computandose a percentagem de plântulas normais. Foi determinado também o teor de água das sementes antes e após cada período de envelhecimento.

Envelhecimento acelerado (solução saturada de NaCl) - esta avaliação foi conduzida da mesma maneira relatada para procedimento tradicional, adicionando-se porém, $40 \mathrm{~mL}$ de solução saturada de $\mathrm{NaCl}$ ao fundo de cada caixa plástica, em substituição à água, proporcionando ambiente com 76\% UR (Jianhua e McDonald, 1996).

Emergência em campo - foram instaladas quatro repetições de 100 sementes, semeadas em canteiros no espaçamento de 1,0m x 0,20m, fazendo uso de irrigação. A avaliação foi realizada aos 15 dias após a semeadura, computando-se as percentagens de plântulas emergidas.

Deterioração controlada - o grau de umidade das sementes foi ajustado artificialmente para dois níveis diferentes, 20\% e 24\%, através do método da atmosfera úmida (Rossetto et al., 1995). Para tanto, foram colocados 40mL de água em caixas plásticas transparentes (11,5x11; 5x3,5cm) com suportes para apoio de uma tela metálica e, sobre esta, distribuídas amostras de aproximadamente 9,0g de sementes, em camada uniforme. As caixas foram tampadas e mantidas em germinador a $20^{\circ} \mathrm{C}$. durante o umedecimento artificial, o grau de umidade de cada amostra foi monitorado mediante pesagens sucessivas, até se obter os valores desejados. $\mathrm{O}$ tempo médio de umedecimento é de 24 a 32 horas. Uma vez obtidos os graus de umidade planejados, cada amostra foi colocada em embalagem plástica revestida por alumínio , fechada hermeticamente e mantida por cinco dias em câmara fria $\left(8-10^{\circ} \mathrm{C}\right)$,com a finalidade de assegurar distribuição uniforme da água no interior das sementes. Em seguida, as amostras foram mantidas em banho-maria a $41^{\circ} \mathrm{C}$ e $45^{\circ} \mathrm{C}$, durante 24h. Posteriormente, foram imersas rapidamente em água fria para reduzir a temperatura, sendo instalado em seguida o teste de germinação (Powell, 1995). A avaliação foi efetuada aos quatro dias após a semeadura, computando-se a percentagem média de plântulas normais para cada lote. Foi determinado, também, o grau de umidade das sementes após esse período de envelhecimento artificial, segundo os critérios estabelecidos nas Regras para Análise de Sementes (Brasil, 1992).

Procedimento estatístico - o delineamento experimental utilizado foi o inteiramente casualizado. Os dados obtidos em cada teste foram analisados separadamente através da análise de variância. As médias obtidas em cada teste foram comparadas pelo teste de Tukey ao nível de 5\% de probabilidade. No teste de deterioração controlada, os tratamentos constituíram-se da combinação de dois graus de umidade e duas temperatura (2x2), totalizando quatro tratamentos. Os dados obtidos no teste de deterioração 
controlada e emergência em campo foram analisados mediante correlação simples ao nível de 1\% de probabilidade. Para os cálculos estatísticos utilizou-se o Sistema de análise Estatística - ASSISTAT - Professor Francisco de Assis Santos e Silva CTRN/UFCG.

\section{RESULTADOS E DISCUSSÃO}

O teste de germinação não diferenciou os níveis de qualidade do Lote 1, esse teste é conduzido em condições controladas, podendo fornecer resultados que superestimam o potencial fisiológico das sementes. $\mathrm{O}$ teste de envelhecimento acelerado com solução saturada de $\mathrm{NaCl}$ não foi sensível em detectar as diferenças no potencial fisiológico das amostras avaliadas (Tabela 1). Entretanto, Ramos et al. (2004) avaliaram a qualidade de sementes de rúcula através do teste de envelhecimento acelerado com solução saturada de $\mathrm{NaCl}$ e verificaram que a temperatura de $41^{\circ} \mathrm{C}$ durante 48 horas e a $45^{\circ} \mathrm{C}$ por 96 horas, proporcionou a mesma separação dos lotes verificada pela emergência de plântulas.

O teste de primeira contagem de germinação e comprimento de plântulas estratificaram o Lote 1 em duas faixas de qualidade (Tabela 1 ), evidenciando a pouca sensibilidade destes testes em distinguir pequenas diferenças de vigor. O teste de primeira contagem foi considerado como um índice adequado para monitorar o vigor de sementes de melancia durante a maturação (Alvarenga et al., 1984) e diferenciar o vigor de lotes de sementes de pepino (Bhering et al., 2000). Embora a primeira contagem do teste de germinação seja considerada um indicativo do vigor, sabe-se que durante o processo de deterioração das sementes, a redução da velocidade de germinação não está entre os primeiros eventos relacionados por Delouche e Baskin (1973). Sendo assim, é um teste que, normalmente, não detecta pequenas diferenças de vigor.

O teste de envelhecimento acelerado tradicional e classificação do vigor de plântulas apresentaram sensibilidade no ranqueamento dos níveis de qualidade. Embora estatisticamente estes dois testes tenham ranqueado o Lote 1 em três categorias de vigor (Tabela 1), constata-se em valores absolutos uma tendência compatível com a ordenação dos níveis de qualidade obtidos artificialmente e pelo teste em campo. A capacidade do teste de envelhecimento acelerado em detectar diferenças na qualidade das sementes de soja e ervilha foi também observada por Kulik e Yaklich (1982) e Caliari e Marcos Filho (1990). Sua eficiência em refletir a capacidade de emergência de plântulas, em campo, foi relatada por Grabe (1976). O teste de envelhecimento acelerado também se relacionou com a emergência das plântulas de cebola a campo, além de identificar lotes com diferentes níveis de vigor (Piana et al.,1995). Resultados semelhantes foram obtidos com sementes de cenoura (Trigo e Trigo, 1995b), pepino (Trigo e Trigo, 1995a), brócolis (Mello et al., 1999) e tomate (Panobianco e Marcos Filho, 2001).

$O$ teste de emergência em campo mostrou maior sensibilidade no ranqueamento da qualidade do Lote 1 e em números absolutos diferenciou os seis níveis de qualidade. Este teste tem sido utilizado pelas empresas e produtores de sementes na época de comercialização dos lotes. A visualização dos estandes de campo permite ao comprador uma seleção mais adequada dos lotes, bem como maior confiança no produto adquirido. É o teste de referência quando se procura através da pesquisa avaliar a eficiência dos testes de vigor.

O teste de deterioração controlada embora estatisticamente não tenha diferenciado os seis níveis de qualidade do Lote 1 , em valores absolutos permitiu o

TABELA 1. Percentagens médias obtidas para o teste de germinação (TG), primeira contagem de germinação (PCG), comprimento de plântulas (CP), classificação de vigor de plântulas (CVP), emergência em campo (EC), envelhecimento acelerado tradicional (EA H2O) e envelhecimento acelerado com solução saturada de $\mathrm{NaCl}$ (EA SS) com diferentes níveis de qualidade de sementes de rúcula. Lote 1

\begin{tabular}{|c|c|c|c|c|c|c|c|}
\hline \multirow{2}{*}{ Níveis de qualidade } & \multirow{2}{*}{ TG $(\%)$} & \multirow{2}{*}{ PCG (\%) } & \multicolumn{2}{|c|}{ EA $(\%)$} & \multirow{2}{*}{$\mathrm{EC}(\%)$} & \multirow{2}{*}{ CVP (\%) } & \multirow{2}{*}{$\mathrm{CP}(\mathrm{cm})$} \\
\hline & & & $(\mathrm{H} 2 \mathrm{O})$ & SS & & & \\
\hline 1 & $92 \mathrm{a}$ & $89 a$ & $76 \mathrm{a}$ & $82 \mathrm{a}$ & $88 \mathrm{a}$ & $77 \mathrm{a}$ & $6,4 \mathrm{a}$ \\
\hline 2 & $90 \mathrm{a}$ & $88 \mathrm{a}$ & $72 \mathrm{a}$ & $81 \mathrm{a}$ & $83 a b$ & $73 \mathrm{ab}$ & $6,4 \mathrm{a}$ \\
\hline 3 & $91 \mathrm{a}$ & $88 \mathrm{a}$ & $72 \mathrm{a}$ & $72 \mathrm{a}$ & $80 \mathrm{~b}$ & $61 \mathrm{abc}$ & $5,6 a b$ \\
\hline 4 & $85 \mathrm{a}$ & $83 \mathfrak{b}$ & $53 \mathrm{~b}$ & $73 \mathrm{a}$ & $71 \mathrm{c}$ & $50 \mathrm{c}$ & $5,1 \mathrm{~b}$ \\
\hline 5 & $80 \mathrm{a}$ & $78 \mathrm{~b}$ & $44 \mathrm{~b}$ & $72 \mathrm{a}$ & $65 c$ & $57 \mathrm{bc}$ & $5,3 \mathrm{~b}$ \\
\hline 6 & $80 \mathrm{a}$ & $77 \mathrm{~b}$ & $31 \mathrm{c}$ & $72 \mathrm{a}$ & $53 \mathrm{~d}$ & $48 \mathrm{c}$ & $5,1 \mathrm{~b}$ \\
\hline CV (\%) & 4,0 & 4,5 & 10,2 & 7,5 & 4,4 & 10,2 & 5,8 \\
\hline
\end{tabular}

*Médias seguidas de mesma letra na coluna, não diferem entre si em nível de $5 \%$ de probabilidade, pelo teste de Tukey. 
ranqueamento em níveis de vigor, as combinações $41^{\circ} \mathrm{C}, 24 \mathrm{~h}$, $20 \%$ e $41^{\circ} \mathrm{C}$, 24h, $24 \%$ mostraram coerência com os níveis de vigor obtidos artificialmente e concordância com os resultados do teste de emergência em campo (Tabela 2). Resultados consistentes com esse teste para a avaliação do vigor de sementes de hortaliças, no Brasil, também foram obtidos por Panobianco e Marcos Filho (1998), com pimentão; Rodo et al. (1998b) e Panobianco e Marcos Filho (2001), com tomate; e Sader et al. (2001), com brócolis.

O teste de deterioração controlada é recomendado, principalmente, para hortaliças (Powell e Matthews, 1981; Mendonça et al., 2000), no entanto pesquisadores brasileiros como Rosseto e Marcos Filho (1995) e Marcos Filho et al. (2001) têm estudado este teste para sementes de soja.

As metodologias do teste de deterioração controlada ( $\left.41^{\circ} \mathrm{C}, 24 \mathrm{~h}, 20 \%\right)$ e $\left(41^{\circ} \mathrm{C}, 24 \mathrm{~h}, 24 \%\right)$ apresentaram correlação significativa com a emergência em campo $\left(r^{2}=0,9571\right.$ e $r^{2}=$ 0,9206) (Figura 1). A classificação dos níveis de qualidade do Lote 1 foi similar a verificada para o teste de emergência em campo (Figura 1), confirmando os resultados obtidos na comparação de médias e evidenciando a eficiência do teste de deterioração controlada para avaliar o vigor de sementes de rúcula. Os testes de vigor devem apresentar relação com a emergência de plântulas em campo, rapidez, objetividade, simplicidade, baixo custo e reprodutibilidade (Delouche, 1976; AOSA, 1983; Tekrony, 1983). São considerados eficientes os testes que permitem separar lotes de sementes em diferentes categorias de vigor, principalmente quando possuem poder germinativo semelhante (Tekrony, 1983).

É fundamental que um determinado teste permita distinguir com elevado grau de segurança e consistência os lotes de alto vigor daqueles que apresentam baixo vigor. Em outras palavras, que permita distinguir eficientemente os lotes

TABELA 2. Percentagens médias obtidas para o teste de deterioração controlada com diferentes níveis de qualidade de sementes de rúcula. Lote 1

\begin{tabular}{ccccc}
\hline \multirow{2}{*}{ Níveis de qualidade } & \multicolumn{4}{c}{ Deterioração controlada (\%) } \\
& $41 \% 24 \mathrm{~h}$ & $45 \% 24 \mathrm{~h}$ \\
\cline { 2 - 5 } & $20 \%$ & $24 \%$ & $20 \%$ & $24 \%$ \\
\hline 1 & $46 \mathrm{a}$ & $30 \mathrm{a}$ & $2 \mathrm{a}$ & 0 \\
2 & $34 \mathrm{ab}$ & $20 \mathrm{ab}$ & $0 \mathrm{a}$ & 0 \\
3 & $29 \mathrm{~b}$ & $16 \mathrm{~b}$ & $0 \mathrm{a}$ & 0 \\
4 & $25 \mathrm{~b}$ & $11 \mathrm{bc}$ & $0 \mathrm{a}$ & 0 \\
5 & $11 \mathrm{c}$ & $10 \mathrm{bc}$ & $0 \mathrm{a}$ & 0 \\
6 & $8 \mathrm{c}$ & $2 \mathrm{c}$ & $0 \mathrm{a}$ & 0 \\
\hline CV $(\%)$ & 18,1 & 27,2 & - & - \\
\hline
\end{tabular}

* Médias seguidas de mesma letra na coluna, não diferem entre si em nível de $5 \%$ de probabilidade, pelo teste de Tukey.
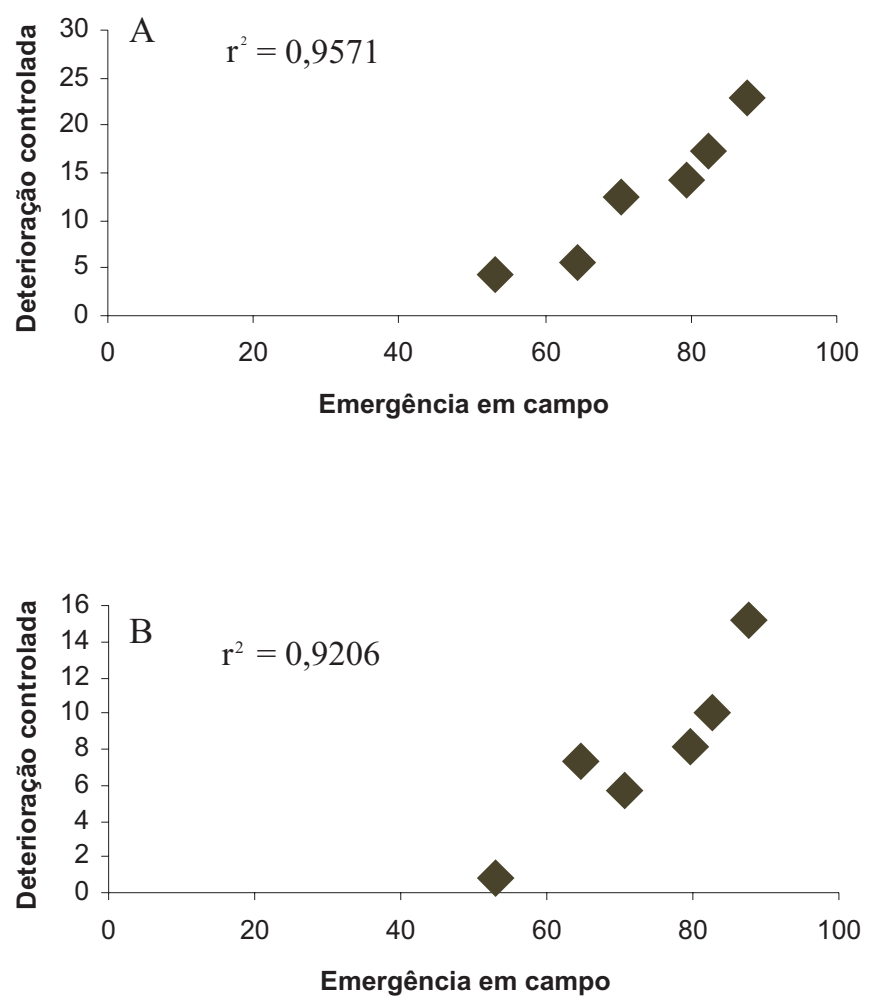

FIGURA 1. Correlação entre o teste de emergência em campo e o teste de deterioração controlada $A\left(41^{\circ} \mathrm{C}, 24 \mathrm{~h}\right.$, $20 \%)$ e $B\left(41^{\circ} \mathrm{C}, 24 \mathrm{~h}, 24 \%\right)$ em sementes de rúcula. Lote 1.

de maior e menor probabilidade de apresentar bom desempenho após a semeadura e/ou durante o armazenamento (Marcos Filho et al., 1987).

Na Tabela 3 observa-se que os testes de vigor não detectaram diferenças de qualidade do Lote 2. O teste de envelhecimento acelerado tradicional detectou apenas o nível de mais baixo vigor. Entretanto, Panobianco (2000) verificou que o teste de envelhecimento acelerado, tanto pelo método tradicional como pelo uso de solução saturada de $\mathrm{NaCl}$, mostrou-se adequado para avaliar o vigor de sementes de tomate. Também Torres (2002), utilizando a combinação $41^{\circ} \mathrm{C}$ por 72 horas, verificou que ambos os métodos de envelhecimento mostraram-se promissores para avaliar o potencial fisiológico de sementes de melão.

O resultado do teste de germinação mostra a alta qualidade do Lote 2 (94\%) que mesmo submetido a envelhecimento artificial manteve a germinação do nível de qualidade mais baixo em 90\%, apresentando uma redução com o estresse artificial de apenas quatro pontos percentuais.

O teste de deterioração controlada $\left(41^{\circ} \mathrm{C}, 24 \mathrm{~h}, 20 \%\right)$, quanto ao ranqueamento dos níveis de qualidade, apresentou 
TABELA 3. Percentagens médias obtidas para o teste de germinação (TG), primeira contagem de germinação (PCG), comprimento de plântulas (CP), classificação de plântulas (CLP), emergência em campo (EC), envelhecimento acelerado tradicional (EA H2O) e envelhecimento acelerado com solução saturada de $\mathrm{NaCl}$ (EA SS) com diferentes níveis de qualidade de sementes de rúcula. Lote 2.

\begin{tabular}{|c|c|c|c|c|c|c|c|}
\hline \multirow{2}{*}{ Níveis de qualidade } & \multirow[t]{2}{*}{$\mathrm{TG}(\%)$} & \multirow[t]{2}{*}{ PCG (\%) } & \multicolumn{2}{|c|}{$\operatorname{EA}(\%)$} & \multirow[t]{2}{*}{$\mathrm{EC}(\%)$} & \multirow[t]{2}{*}{ CVP (\%) } & \multirow{2}{*}{$\begin{array}{c}\mathrm{CP} \\
(\mathrm{cm})\end{array}$} \\
\hline & & & $(\mathrm{H} 2 \mathrm{O})$ & $\mathrm{SS}$ & & & \\
\hline 1 & $94 \mathrm{a}$ & $93 \mathrm{a}$ & $89 a$ & $88 \mathrm{a}$ & $84 \mathrm{a}$ & $61 \mathrm{a}$ & $5,6 a$ \\
\hline 2 & $95 \mathrm{a}$ & $95 \mathrm{a}$ & $86 \mathrm{ab}$ & $85 \mathrm{a}$ & $83 \mathrm{a}$ & $52 \mathrm{a}$ & $5,3 \mathrm{a}$ \\
\hline 3 & $94 \mathrm{a}$ & $94 \mathrm{a}$ & $82 \mathrm{ab}$ & $88 \mathrm{a}$ & $78 \mathrm{a}$ & $50 a$ & $5,3 \mathrm{a}$ \\
\hline 4 & $93 a$ & $92 \mathrm{a}$ & $86 \mathrm{ab}$ & $90 \mathrm{a}$ & $83 a$ & $54 \mathrm{a}$ & $5,4 \mathrm{a}$ \\
\hline 5 & $91 \mathrm{a}$ & $91 \mathrm{a}$ & $83 \mathrm{ab}$ & $90 a$ & $80 \mathrm{a}$ & $55 \mathrm{a}$ & $5,5 \mathrm{a}$ \\
\hline 6 & $90 \mathrm{a}$ & $90 \mathrm{a}$ & $81 \mathrm{~b}$ & $87 \mathrm{a}$ & $82 \mathrm{a}$ & $54 \mathrm{a}$ & $5,4 \mathrm{a}$ \\
\hline $\mathrm{CV}(\%)$ & 3,3 & 3,1 & 3,6 & 5,3 & 12,2 & 15,0 & 8,0 \\
\hline
\end{tabular}

*Médias seguidas de mesma letra na coluna, não diferem entre si em nível de 5\% de probabilidade, pelo teste de Tukey.

comportamento semelhante aos demais testes de vigor e concordância com os resultados da emergência em campo (Tabelas 3 e 4). Por outro lado, a metodologia de $41^{\circ} \mathrm{C}, 24 \mathrm{~h}$, 24\% separou o Lote 2 em níveis de qualidade a semelhança dos obtidos artificialmente, embora nenhum dos testes de vigor utilizados tenham apresentado esta sensibilidade.

A deterioração controlada é um teste relativamente simples, não exigindo conhecimentos sofisticados, investimentos significativos e não apresenta dificuldades acentuadas para padronização. Dessa forma, tem sido utilizado para detectar diferenças no vigor de lotes de sementes e para verificar o potencial de armazenamento de sementes de diversas hortaliças como cenoura, cebola, alface e brássicas (Matthews, 1980; Powell e Matthews, 1981; Powell e Matthews, 1984; Wang et al., 1994).

De acordo com Powell e Matthews (1981), a seleção do grau de umidade apropriado a uma dada temperatura é um dos pré-requisitos para o sucesso da utilização do teste de deterioração controlada. Trabalhando com sementes de nabo a 7,0; 18,0; 21,0 e 22,0\% de umidade, Powell e Matthews (1981) verificaram que o grau de umidade de $21,0 \%$ possibilitou distinguir diferenças entre os lotes que não foram reveladas quando a deterioração foi realizada com sementes com 18,0\% de umidade. Entretanto, quando utilizaram sementes com 22,0\% de umidade, a germinação de um dos lotes declinou drasticamente após o estresse, mostrando a grande sensibilidade de lotes de baixa qualidade às condições do teste.

Com relação aos dados referentes ao grau de umidade das sementes após o período em banho-maria, no teste de deterioração controlada (Tabelas 5 e 6), pode-se observar que as sementes permaneceram, praticamente com os mesmos graus de umidade em relação ao início do teste. Assim, a técnica utilizada para a deterioração controlada mostrou-se
TABELA 4. Percentagens médias obtidas para o teste de deterioração controlada com diferentes níveis de qualidade de sementes de rúcula. Lote 2

\begin{tabular}{ccccc}
\hline \multirow{2}{*}{ Níveis de qualidade } & \multicolumn{4}{c}{ Deterioração controlada (\%) } \\
& $41 \% 24 \mathrm{~h}$ & $45 \%$ 24h \\
\cline { 2 - 5 } & $20 \%$ & $24 \%$ & $20 \%$ & $24 \%$ \\
\hline 1 & $84 \mathrm{a}$ & $42 \mathrm{a}$ & $0 \mathrm{a}$ & 0 \\
2 & $84 \mathrm{a}$ & $34 \mathrm{ab}$ & $2 \mathrm{a}$ & 0 \\
3 & $83 \mathrm{a}$ & $30 \mathrm{~b}$ & $3 \mathrm{a}$ & 0 \\
4 & $83 \mathrm{a}$ & $16 \mathrm{c}$ & $0 \mathrm{a}$ & 0 \\
5 & $81 \mathrm{a}$ & $14 \mathrm{c}$ & $0 \mathrm{a}$ & 0 \\
6 & $81 \mathrm{a}$ & $6 \mathrm{c}$ & $0 \mathrm{a}$ & 0 \\
\hline $\mathrm{CV}(\%)$ & 3 & 18,3 & - & - \\
\hline
\end{tabular}

*Médias seguidas de mesma letra na coluna, não diferem entre si em nível de $5 \%$ de probabilidade, pelo teste de Tukey.

eficiente, no sentido de manter constante o grau de umidade das sementes durante o decorrer do teste. Concordando, deste modo, com as afirmações de Krzyzanowski e Vieira (1999) que o teste de deterioração controlada controla melhor o grau de umidade da semente e a temperatura durante o envelhecimento que o teste de envelhecimento acelerado.

Os resultados do teor de água atingido após a realização do teste de envelhecimento acelerado tradicional e com solução saturada de $\mathrm{NaCl}$ encontram-se nas Tabelas 5 e 6. Observase que, sementes de rúcula envelhecidas, no procedimento tradicional, atingiram teores de água mais elevados e apresentaram variações mais acentuadas entre os níveis de qualidade, que o envelhecimento acelerado com solução salina. Os resultados encontrados concordam com os obtidos por Ramos et al., (2004).

A disponibilidade de métodos eficientes para a avaliação do vigor permite identificar lotes que apresentam maior probabilidade de se estabelecer adequadamente em campo, eliminando aqueles que não satisfazem os padrões 
TABELA 5. Grau de umidade inicial (UI) e após os testes de envelhecimento acelerado tradicional (EA H2O), envelhecimento acelerado com solução saturada de $\mathrm{NaCl}$ (EA SS) e deterioração controlada de sementes de rúcula, com diferentes níveis de qualidade. Lote 1.

\begin{tabular}{|c|c|c|c|c|c|c|c|}
\hline \multirow{3}{*}{ Níveis de qualidade } & \multirow{3}{*}{ UI (\%) } & \multicolumn{4}{|c|}{ Deterioração controlada (\%) } & \multicolumn{2}{|c|}{ EA $(\%)$} \\
\hline & & \multicolumn{2}{|c|}{$41^{\circ} \mathrm{C} / 24 \mathrm{~h}$} & \multicolumn{2}{|c|}{$45^{\circ} \mathrm{C} / 24 \mathrm{~h}$} & \multirow[t]{2}{*}{$(\mathrm{H} 2 \mathrm{O})$} & \multirow[t]{2}{*}{$\mathrm{SS}$} \\
\hline & & $20 \%$ & $24 \%$ & $20 \%$ & $24 \%$ & & \\
\hline 1 & 5,5 & 19,7 & 24,3 & 20,3 & 24,1 & 28,4 & 10,0 \\
\hline 2 & 5,7 & 19,9 & 23,9 & 19,2 & 23,5 & 18,7 & 9,9 \\
\hline 3 & 5,8 & 19,8 & 24,1 & 19,7 & 23,8 & 30,8 & 9,8 \\
\hline 4 & 5,8 & 20,0 & 24,0 & 20,4 & 24,4 & 21,3 & 10,1 \\
\hline 5 & 5,5 & 20,1 & 23,8 & 20,5 & 24,3 & 25,5 & 10,4 \\
\hline 6 & 5,7 & 20,5 & 24,4 & 20,1 & 24,4 & 24,3 & 10,1 \\
\hline
\end{tabular}

*Médias seguidas de mesma letra na coluna, não diferem entre si em nível de 5\% de probabilidade, pelo teste de Tukey.

TABELA 6. Grau de umidade inicial (UI) e após os testes de envelhecimento acelerado tradicional (EA H2O), envelhecimento acelerado com solução saturada de $\mathrm{NaCl}$ (EA SS) e deterioração controlada de sementes de rúcula, com diferentes níveis de qualidade. Lote 2 .

\begin{tabular}{cccccccc}
\hline \multirow{2}{*}{$\begin{array}{l}\text { Níveis de } \\
\text { qualidade }\end{array}$} & UI (\%) & \multicolumn{3}{c}{ Deterioração controlada (\%) } & \multicolumn{3}{c}{ EA (\%) } \\
\cline { 3 - 6 } & & $20 \%$ & $24 \%$ & $20 \%$ & $24 \%$ & $(\mathrm{H} 2 \mathrm{O})$ & $\mathrm{SS}$ \\
\hline & 6,0 & 20,2 & 24,0 & 20,1 & 23,7 & 27,6 & 10,1 \\
2 & 6,3 & 19,9 & 23,8 & 20,4 & 24,0 & 21,5 & 12,1 \\
3 & 6,1 & 20,2 & 23,9 & 20,3 & 24,0 & 15,2 & 12,2 \\
4 & 6,3 & 19,8 & 24,2 & 20,1 & 23,8 & 31,8 & 12,3 \\
5 & 6,4 & 20,4 & 24,0 & 19,8 & 24,0 & 24,5 & 12,6 \\
6 & 6,2 & 20,5 & 23,9 & 19,9 & 24,3 & 25,7 & 12,0 \\
\hline
\end{tabular}

*Médias seguidas de mesma letra na coluna, não diferem entre si em nível de 5\% de probabilidade, pelo teste de Tukey.

estabelecidos pela empresa. A presente pesquisa evidencia os testes de deterioração controlada, envelhecimento acelerado tradicional e classificação do vigor de plântulas como indicados para avaliar o vigor de sementes de rúcula.

\section{CONCLUSÕES}

O teste de deterioração controlada conduzido a $41^{\circ} \mathrm{C}$, com umidade das sementes de $20 \%$ e período de exposição de $24 \mathrm{~h}$ é eficiente para avaliar o potencial fisiológico de sementes de rúcula.

Os testes de envelhecimento acelerado tradicional, classificação de vigor de plântulas e deterioração controlada são indicados para avaliar o vigor de sementes de rúcula.

\section{REFERÊNCIAS}

ALVARENGA, E.M.; SILVA, R.F.; ARAÚJO, E.F.; CARDOS, A.A.
Influência da idade e armazenamento pós-colheita dos frutos na qualidade de sementes de melancia. Horticultura Brasileira, Brasília, v.2, n.2, p.5-8, 1984.

ASSOCIATION OF OFFICIAL SEED ANALYSTS. Seed vigor testing handbook. Lincoln, 1983. 93p. (Contribuition, 32).

BHERING, M.C.; DIAS, D.C.F.S.; GOMES, J.M.; BARROS, D.I. Métodos para avaliação do vigor de sementes de pepino. Revista Brasileira de Sementes, Londrina, v.22, n.2, p.171-175, 2000.

BRASIL.Ministério da Agricultura e da Reforma Agrária. Regras para Análise de Sementes.Brasília:SNDA/DNPV/CLAV, 1992. 365p.

CALLIARI, M.F.; MARCOS FILHO, J. Comparação entre métodos para avaliação da qualidade fisiológica de sementes de ervilha (Pisum sativum L.). Revista Brasileira de Sementes. Brasília, v. 12, n. 3, p.52-75. 1990.

DELOUCHE, J.C. Standardization of vigour testes. Journal of Seed Technology, Zürich, v.1, n.2, p.75-85, 1976.

DELOUCHE, J.C.; BASKIN, C.C. Accelerated aging techniques for predicting the relative storability of seed lots. Seed Sciencie and Technology, v.1, n.2, p.427-452, 1973.

GLOBIRSON, D. The quality of lettuce seed harvested at different 
times after anthesis. Seed Sciencie and Technology, Zürich, v.9, p.861-866, 1981.

GRABE, D.F. Measurement of seed vigor. Journal of Seed Technology. Springfield, v. 1, n. 2, p. 18-31, 1976.

HAMPTON, J.G.; COOLBEAR, P. Potencial versus actual seed performance can vigour testing provide an answer? Seed Sciencie and Technology, Zürich, v.18, p.215-228, 1990.

JIANHUA, Z.; McDONALD, M.B. The satured salt accelerated aging test for small seeded crops. Seed Science and Technology, Zürich, v.25, p.123-131, 1996.

KRZYZANOWSKI, F.C.; VIEIRA, R.D. Deterioração controlada. In: KRZYZANOWSKI, F.C.; VIEIRA, R.D.; FRANÇA NETO, J.B. (Ed.) Vigor de sementes: conceitos e testes. Londrina: ABRATES, 1999B. Cap. 6, P. 1-8.

KULIK, M.M. \& YAKLICH, R.W. Evaluation of vigor testes in soybean seeds: relationship of accelerated aging, cold, sand bench and speed of germination testes to field performance. Crop Scicience, Madison, v. 22, n. 4, p. 766-70, 1982.

MARCOS FILHO, J.; NOVEMBRE, A.D.C.; CHAMMA, H.M.C.P. Testes de envelhecimento acelerado e deterioração controlada para avaliação do vigor de sementes de soja. Scientia Agrícola, Piracicaba, v.58, n.2, p.421-426, 2001.

MARCOS FILHO, J.M.; CICERO, S.M.; SILVA, W.R. Avaliação da qualidade das sementes. Piracicaba: FEALQ, 1987. 230p.

MATTHEWS, S. Controlled deterioration: a new vigour test for crop seeds. In: HEBBLETHWAITE, P.D. (Ed). Seed production. London: Butterworths, 1980. p.647-660.

MELLO, S.C.; SPINOLA, M.C.M.; MINAMI,K. Métodos de avaliação da qualidade fisiológica de sementes de brócolos. Scientia Agrícola, Piracicaba, v.56 n.4, p.1151-1155, out./dez. 1999. Suplemento.

MENDONÇA, E.A.F.; RAMOS, N.P.; FESSEL, S.A.; SADER, R. Teste de deterioração controlada em sementes de brocoli (Brassica oleracea L.) var. itálica. Revista Brasileira de Sementes, Brasília, v.22, n.1, p.280-287, 2000.

NAKAGAWA, J. Testes de vigor baseados na avaliação das plântulas. In: VIEIRA, R.D.; CARVALHO, N.M. (Ed.) Testes de vigor em sementes. Jaboticabal: FUNEP, 1994, p.48-85.

PANOBIANCO, M. Avaliação do potencial fisiológico de sementes de tomate. 2000. 152f. Tese (Doutorado em Agronomia) - Escola Superior de Agricultura "Luiz de Queiroz”, Universidade de São Paulo, Piracicaba.

PANOBIANCO, M.; MARCOS FILHO, J. Avaliação do potencial fisiológico de sementes de tomate atreves dos testes de germinação e vigor. Informativo ABRATES, Brasília, v.11, n.2, p.179, res.164, 2001a.

PANOBIANCO, M; MARCOS FILHO, J. Comparação entre métodos para avaliação da qualidade fisiológica de sementes de pimentão. Revista Brasileira de Sementes, Brasília, v.20, n.2, p.306-310, 1998.
PIANA,Z.; TILLMANN, M.A.A. \& MINAMI, K. Avaliação da qualidade fisiológica de sementes de cebola e sua relação com a produção de mudas vigorosas. Revista Brasileira de Sementes, Brasília, v.17, n.2, p.149-153, 1995.

POWELL, A.A. The controlled deterioration test. In: INTERNATIONAL SEED TESTING ASSOCIATION. Seed vigour testing seminar. Zurich, 1995. p.73-87.

POWELL, A.A.; MATTHEWS, S. Evaluation of controlled deterioration, a new vigour test for small seeds vegetables. Seed Science and Technology, Zürich, v. 9, n.2, p.633-640, 1981.

POWELL, A.A.; MATTHEWS, S. Prediction of the storage potential of onion seed under commercial storage conditions. Seed Science and Technology, Zürich, v.12, n.2, p.641-647, 1984.

RAMOS, N.P.; FLOR, E.P.O.; MENDONÇA, E.A.F.; MINAMI, K. Envelhecimento acelerado em sementes de rúcula (Eruca sativa L.). Revista Brasileira de Sementes, Pelotas, v.26, n.1, p.98-103, 2004.

RODO, A.B.; TILLMANN, M.A.A.; VILLELA, F.A. Testes de vigor na avaliação da qualidade fisiológica de sementes de tomate. Revista Brasileira de Sementes, Londrina, v.20, n.1, p.23-28, 1998b.

ROSSETO, C.A.V.; MARCOS FILHO, J. Comparação entre métodos de envelhecimento acelerado e de deterioração controlada para avaliação da qualidade fisiológica de sementes de soja. Scientia Agrícola, Piracicaba, v.52, n.1, p.123-132, 1995.

ROSSETO, C.V.A.; FERNANDEZ, E.M.; MARCOS FILHO, J. Metodologias de ajunte do grau de umidade e comportamento das sementes de soja no teste de germinação. Revista Brasileira de Sementes, Brasília, v.17, n.2, p.171-178, 1995.

SADER, R.; MENDONÇA, E.A.F.; RAMOS, N.P.; FESSEL, S.A. Teste de deterioração controlada em sementes de brócolis (Brassica oleracea L. var. itálica). Informativo ABRATES, Curitiba, v.11, n.2, p.175, 2001. /Apresentado ao 12. Congresso Brasileiro de Sementes, Curitiba, 2001/.

TEKRONY, D.M. Seed vigour testing - 1982. Journal of Seed Technology, Springfield, v.8, n.1, p.55-60, 1983.

TORRES, S.B. Métodos para avaliação do potencial fisiológico de sementes de melão. Piracicaba, 2002. 103f. Tese (Doutorado) Escola Superior de Agricultura “Luiz Queiroz”, Universidade de São Paulo.

TRIGO, M.F.O.O.; TRIGO, F.L.N. Avaliação do vigor em sementes de pepino (Cucumis sativus L.). Informativo ABRATES, Brasília, v.5, n.2, p.131, 1995a.

TRIGO, M.F.O.O.; TRIGO, F.L.N. Determinação da qualidade fisiológica de sementes de cenoura. Informativo ABRATES, Brasília, v.5, n.2, p.134, 1995b.

WANG, Y.R.; HAMPTON, J.G.; HILL, M.J. Red clover vigour testing: effects of three test variables. Seed Science and Technology, Zürich, v.22, n.1, p.99-105, 1994.

WURR, D.C.E.; FELLOUS, J.R. The effect of time of seedling emergence of crisp lettuce on time of maturity. Journal of Horticultural Science, v.58, n.4, p.561-566, 1983.

YAMAGUCHI, M. World vegetables: principles, production, and nutritive value. Davis, University of California, 1978. 226p.

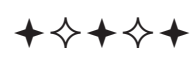

